\title{
Cestodes of Untreated Large Stray Dog Populations in Algeria: A Reservoir for Herbivore and Human Parasitic Diseases
}

\author{
B. Bentounsi ${ }^{1}$, S. Meradi ${ }^{1}$, A. Ayachi ${ }^{1}$ and J. Cabaret ${ }^{*}, 2$ \\ ${ }^{1}$ Laboratoire de Parasitologie, Département Vétérinaire, Université Mentouri, Constantine, Algeria \\ ${ }^{2}$ INRA, IASP, Bat 213, 37380 Nouzilly, France
}

\begin{abstract}
Taeniids are frequent in dogs of Mediterranean countries and most studies have focused on the zoonotic Echinococcus granulosus, although several other species of cestodes are usually collected. We necropsied 127 stray dogs in two areas of eastern Algeria, in order to characterize the cestode communities and the factors that may structure these communities in conditions where anthelmintic treatments are not interfering with infection. The maximum number of species in one single dog was four, among Echinococcus granulosus, Taenia hydatigena, Taenia pisiformis, Taenia multiceps, Dipylidium caninum, or Mesocestoides lineatus. T. hydatigena was the most prevalent in both areas (over 40\%) and E. granulosus had different prevalences (16 versus $42 \%$ ) in the two areas. The associations between cestode species were studied using pairwise and multivariate methods, the latter being more realistic in case of species associations. $E$. granulosus was positively associated with $T$. hydatigena whereas the other species were negatively associated with the group T. hydatigena and E. granulosus. The large use of efficient anthelmintics may modify the structure of these communities. Risk factors were evaluated for each species of cestode. Older dogs harbored more T. hydatigena and less $T$. multiceps, M. lineatus and D. caninum. The latter was less frequent in rural areas.
\end{abstract}

\section{INTRODUCTION}

Taeniids are frequent in intestine of stray dogs in Mediterranean countries [1] Algeria, [2] Tunisia, [3] Morocco, [4] Spain, and [5] Israel, among others]. Apart from Dipylidium caninum which concerns only dogs, the other cestode species as larval stage may infect herbivores (Taenia hydatigena-Cysticercus tenuicollis mostly in sheep, Taenia pisiformis- Cysticercus pisiformis of rabbits and hares, Taenia multiceps- mostly in sheep Coenurus cerebralis and rarely humans [6], Mesocestoides lineatus in many mammals) or man and herbivores (E. granulosus). The main interest for public health in those countries is the presence of the zoonotic Echinococcus granulosus cestode [7]. E. granulosus is very frequent in Algeria with prevalence in dogs ranging from 9 to $41 \%$ [8] according to the regions. In the eastern part of Algeria, the condemnations of lung and liver in cattle sheep or goats are frequent in relation to hydatid cysts. In 2003, $20.8 \%$ of lungs and $14.8 \%$ of liver were condemned in cattle, due to echinococcosis (our unpublished data from Batna region), which is indicative of high prevalence of E. granulosus.

The assemblage of species (community) may depend on a variety of factors in nature, such as climate, individual, age, or sex-induced host resistance, and interaction between species. Efficient anthelmintic treatments when frequent may interfere with intensity and assemblages of cestodes. Treatments are not practised in most dogs in Algeria in contrast with most European countries $[9,10]$ where dogs are kept as companion animals. No highly efficient drug was

*Address correspondence to this author at INRA, IASP, Bat 213, 37380 Nouzilly, France; Tel: +33 2 47427768; Fax: +33 2 47427774;

E-mail: jacques.cabaret@tours.inra.fr available in Algeria for years due to restricted imports and flubendazole/niclosamide low dosage preparation with low efficacy has been used among other dogs than stray dogs; and this is a situation with very low anthelmintic pressure. Stray dogs or semi-stray dogs (returning home only at night) are numerous, and they have an easy access to condemned organs and lesions of cestodes from herbivores in butchers shop or from family abattoirs in rural zones, as in Tunisia [11] where over $60 \%$ of parasitized organs are available, which may account for high incidence reported in previous surveys in Algeria. The evaluation of associations of cestodes may give an idea on the possibility of multiple dangers for herbivores and man. The intensity of associations determined under natural conditions may correspond to similarities of life cycle. It means that associations in natural infestations do not necessarily reflect interactions between parasite species. Associations between parasites can be estimated pairwise or more efficiently with multivariate analyses [12]. We will investigate the presence and associations of dog cestodes in two locations in eastern Algeria, in the light of putative interactions between species and classical factors such as sex and age.

\section{MATERIALS AND METHODOLOGY}

\section{Surveys}

The first survey was undertaken in 1981 in Constantine dogs. One third of the sampling was from rural areas and the rest from peri-or urban areas. The second survey was undertaken in 2005 in Batna dogs and few were collected in rural areas (Table 1). Both towns are located in the eastern part of Algeria and are $120 \mathrm{~km}$ apart. The climate is semiarid with $594 \mathrm{~mm}$ yearly rainfalls with four dry-months in summer; the winters are fresh with average monthly minimal temperature comprised between 0 and $3^{\circ} \mathrm{C}$. In both surveys, 
each sampling site was visited at night with municipal teams intended to regulate populations of stray-dogs; the locations of stray-dogs were determined and the dogs were killed by hunters. For each killed dog, breed, age (according to teeth with Luquet criteria) sex, and location were noted. Intestines were then collected, the worms were recovered after washing at $40^{\circ} \mathrm{C}$. The cestodes were cleared with acetic acid $10 \%$ and were in some cases colored with chlorhydric carmin. The worms were identified according to $[13,14]$.

Table 1. Hosts and Intestinal Cestode Communities of Stray Dogs in Batna and Constantine Regions of Algeria

\begin{tabular}{|c|c|c|}
\hline & $\begin{array}{c}\text { Batna Region } \\
\qquad(2005)\end{array}$ & $\begin{array}{c}\text { Constantine Region } \\
\text { (1981) }\end{array}$ \\
\hline Dogs & 58 & 69 \\
\hline$\%$ females & 52 & 28 \\
\hline Age in year (SD*) & $2.44(1.82)$ & $2.80(1.67)$ \\
\hline$\%$ rural origin & 14 & 45 \\
\hline Sampled sites & 6 & 7 \\
\hline$\%$ Taenia hydatigena & $40 \pm 13 * *$ & $43 \pm 13(0.81 / 1.71)^{* * *}$ \\
\hline$\%$ Taenia pisiformis & $24 \pm 11$ & $19 \pm 9(2.79 / 8.76)$ \\
\hline$\%$ Taenia multiceps & 2 & $13 \pm 8(0.32 / 1.09)$ \\
\hline$\%$ Echinococcus granulosus & $16 \pm 10$ & $42 \pm 6(2.00 / 6.02)$ \\
\hline$\%$ Mesocestoides lineatus & 0 & $14 \pm 8(10.1 / 10.3)$ \\
\hline \% Dipylidium caninum & $16 \pm 10$ & $57 \pm 12(0.14 / 0.53)$ \\
\hline
\end{tabular}

\section{Statistical Analyses}

The logistic regressions were established on age, sex, sites, rural or urban origin, and cestodes species community. The odds-ratios were calculated from the logistic regressions: for example, a value of five for gender (coded 0 male, and 1 female) indicates that the female dog have a five times higher probability to be infected and a value of 0.5 that females are half less infected than males. The phi-correlation coefficient was used to assess pairwise-associations between species. Correspondence analyses was performed on presence/absence of species with Hill algorithm. The axes were characterized by their variability (inertia in \%); a variable was considered related to another variable (here species) when they were found in proximity on the plane defined by the two axes; this relationship was more intense when variable were located far away from the intersection of the axes. Correspondence analysis is particularly susceptible to dominance by unusual, outlying species; this problem can be rectified by removing the outlying cases or if one wishes to retain these cases in the analysis, an alternative approach is to ignore the first axes that exhibit dominance by outliers and focus attention on subsequent axes. Correspondence analyse is also susceptible to the arch effect: the points are arranged in an arched pattern along the first two axes, rather than a linear pattern as would be expected. This problem can be rectified using detrended correspondence analysis. The calculations were run with SIMSTAT [15] and MVSP [16] softwares.

\section{RESULTS}

\section{Characteristics of Cestodes Communities (Table 1)}

Average species richness (no. of species in hosts) were 1.9 (range 0-4) and 1.0 (range 0-2) in Constantine and Batna, respectively.

Cestodes species prevalences (Table 1) were similar in both regions for most species but were higher in Constantine for E. granulosus and D. caninum. Mesocestoides lineatum was only detected in Constantine.

\section{Presence of Cestodes in Relation with Dog Age and Sex and Rural Origin (Table 2)}

The region was a significant parameter influencing on $D$. caninum (odds-ratio: 12.8), T. multiceps (odds-ratio: 9.99) E. granulosus (odds-ratio: 3.85). Prevalence was higher in older dogs for T. hydatigena and lower for T. multiceps and $M$. lineatus. Urban origin was positively related to higher prevalence of D. caninum.

Table 2. Presence of Cestodes and Dog Characteristics, and Urban or Rural Origin Based on Logistic Regressions in Both Regions

\begin{tabular}{|c|c|c|}
\hline & R2 Nagelkerke* & Odds-Ratio** and Significance \\
\hline T. hydatigena & 0.07 & 1.24: more in older dogs $(p=0.04)$ \\
\hline T. pisiformis & 0.02 & None \\
\hline T. multiceps & 0.20 & $\begin{array}{l}\text { 9.99: more in Constantine }(\mathrm{p}=0.04) \\
0.54: \text { less in older dogs }(\mathrm{p}=0.07)\end{array}$ \\
\hline E. granulosus & 0.12 & 3.85: more in Constantine $(\mathrm{p}=0.004)$ \\
\hline M. lineatus & 0.34 & $\begin{array}{l}\text { 0.00: none in Batna }(\mathrm{p}=0.000) \\
0.54: \text { less in older dogs }(\mathrm{p}=0.08)\end{array}$ \\
\hline D. caninum & 0.32 & $\begin{array}{l}\text { 12.80: more in Constantine }(\mathrm{p}=0.000) \\
\text { 0.79: less in older dogs }(\mathrm{p}=0.09) \\
\text { 0.33: less in rural zone }(\mathrm{p}=0.025)\end{array}$ \\
\hline
\end{tabular}

* This value gives an evaluation of the predictive quality of the logistic regression (maximum 1).

** Odds ratio $>1$ means risk increase; Odds ratio $<1$ means risk decrease.

\section{Associations Between Species Based on Bivariate and Multivariate Analyses}

The pairwise associations are in Table 3. The majority were positive associations, except for $T$. hydatigena and $T$. pisiformis or M. lineatus.

The multivariate estimations (Fig. 1) indicate that:

- E. granulosus and T. hydatigena are co-occurring frequently in Batna and Constantine

- $\quad$ E. granulosus and D. caninum, E. granulosus and T. multiceps, E. granulosus and T. pisiformis are in negative associations in both regions

- $M$. lineatum is in negative association with $E$. granulosus and all other cestodes in the Constantine region where it was only found

To avoid effect of dominance by unusual species, $T$. multiceps in Batna, data were reanalyzed without this species but the same relationships were observed between the other 
Table 3. Phi Correlation Coefficient Between Cestodes Species in Dogs from Batna and Constantine (Italics)

\begin{tabular}{|c|c|c|c|c|c|}
\hline & T. pisiformis & T. multiceps & E. granulosus & D. caninum & M. lineatus \\
\hline \hline T. hydatigena & $\mathbf{- 0 . 2 1}(-\mathbf{0 . 2 7})$ & $0.16(-0.08)$ & $\mathbf{0 . 2 4}(0.14)$ & $0.14(-0.23)$ & $-(-\mathbf{0 . 2 0})$ \\
\hline T. pisiformis & & $\mathbf{0 . 2 4}(0.14)$ & $-0.13(-0.19)$ & $0.13(\mathbf{0 . 2 7})$ & $-(0.12)$ \\
\hline T. multiceps & & & $-0.06(-0.07)$ & $\mathbf{0 . 3 1}$ & $-(\mathbf{0 . 3 3})$ \\
\hline E. granulosus & & & & $-0.18(-0.08)$ & $-(-0.02)$ \\
\hline D. caninum & & & & $-(-0.05)$ \\
\hline
\end{tabular}

Bold: significant at $\mathrm{p}<0.05$ (phi $>0.25)$ or $\mathrm{p}<0.10(\mathrm{phi}>0.21)$.

species (data not shown). Detrended correspondence analyses were undertaken to reduce the arch effect and similar relationships between species were obtained (data not shown).

\section{DISCUSSION}

Few studies are available on the prevalence of the community of cestodes in dogs, since most studies used faecal egg counts (in which all taeniied eggs looks alike). Furthermore, focus has often been directed to E. granulosus, based on necropsy or faeces collection after treatment. The selective efficacy of anthelmintic treatments will modify the proportion of recovered species: Taenia sp are all removed easily by all treatments, whereas Dipylidium and Mesocestoides are less susceptible to anticestode drugs, and E. granulosus is the least susceptible to drugs [14]. The information on E. granulosus has been obtained frequently after treatment and purgation which differs from information obtained at necropsy. Schantz [18] reported that of 46 true $E$. granulosus positive dogs identified on post-mortem examination, 30 dogs produced a positive purge following a single treatment with arecholine. Lahmar et al. [19] indicated that only $43 \%$ of dogs were successfully purged after one arecholine dose; this percentage increased to $76.9 \%$ for two doses of arecholine purgation. Budke et al. [17] proposed an adjusted prevalence for arecholine evaluation (from 8.4 to $12.7 \%$ ) but no information is available for other cestodes.

The prevalence of E. granulosus in dogs ranged from 16 to $42 \%$ in Batna and Constantine, respectively. These figures are in the range of those recorded previously in Algeria [8] or Tunisia [2]. The high infection rate in the Constantine sample may be due to the presence of rural dogs that may feed on infected sheep. Very high prevalence $(62 \%)$ has been recorded in feral dogs in Australia [20] that feed mostly on infected Wallabies and are never treated: this can be considered as a maximum in natural conditions without human intervention.

Other cestodes than E. granulosus found in Algeria are also found in several other sites: D. caninum $(63 \%$ in Mexico [21], 39\% in Iran [21], $14 \%$ in China [22]), Mesocestoides lineatus (27\% in Iran [21], 15\% in China [23]), T. hydatigena (20\% in Belgium [10], 53\% Iran [22], $20 \%$ China [23]).

Within the Algerian cestode community, negative associations between E. granulosus and other cestodes (except T. hydatigena) were recorded, and the easier removal by anti-cestode drug of non-Echinococcus cestodes could

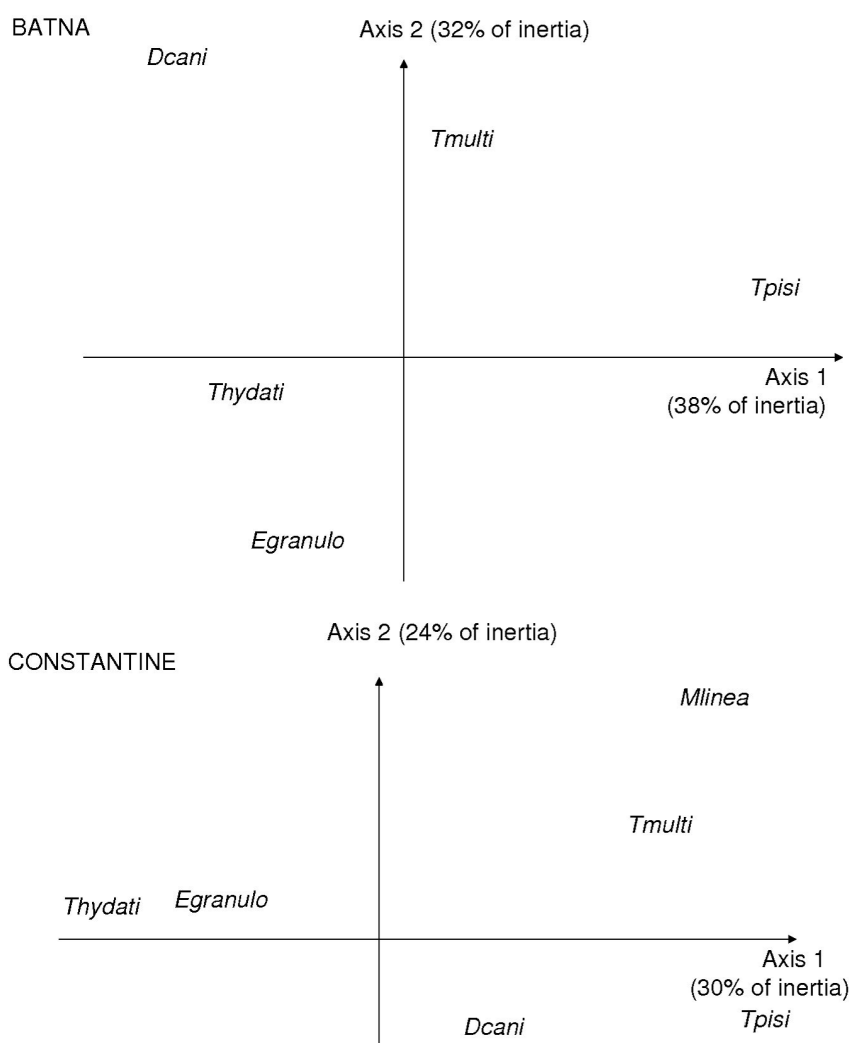

Fig. (1). Correspondence analysis of the dog infestations with Taeniids in Batna and Constantine. (Code for species: Taenia hydatigena: Thydati; Taenia psiformis: Tpisi; Taenia multiceps: Tmulti; Echinococcus granulosus: Egranulo; Dipylidium caninum: Dcani).

possibly promote the extension of E. granulosus. The species associations are evaluated differently according to methodology, and pairwise estimates do not provide much support for negative associations, as also found in an other work [19]. Multivariate estimates provide a more contrasted picture, E. granulosus being associated positively with $T$. hydatigena and negatively to other species. Budke et al. [17] indicated that in the Tibetan plateau, E. granulosus was positively associated with Taenia $s p$. but not to $D$. caninum. Multivariate estimates are more realistic since the different species of cestodes may interact, and thus a pairwise estimate is biased (see Portoles et al. [12]). The activity of dogs could also modify the structure of cestode community: it has been speculated that $T$. multiceps is more expected in sheepdogs, and that $T$. pisiformis in hunting dogs, $T$. hydatigena and E. granulosus in butcher's dogs [14]. Several 
risk factors concerning Echinococcus sp. were described in Tibet [17]: male dogs were more likely to be infected (which was not recorded in our study) and dogs allowed to roam were more likely to be infected.

The associations were established on presence/absence data, which may not be fully appropriate for E. granulosus, which may attain mean abundance over 500 worms [2], since the multivariate method for analysing associations [12] was established on cestodes with low mean abundance (less than 10 worms). However the number of worms (Constantine survey) remained fairly low and suggests that the method we used for interpreting species assemblages in communities is probably convenient.

\section{CONCLUSIONS}

The communities of cestodes in stray dogs of Algeria are diverse and relatively species rich, which explains the high prevalence of larval cestodoses in herbivore and man. The presence of each species was related to various parameters among which region, age of $\mathrm{dog}$, or rural origin, depending on species. E. granulosus was positively associated to $T$. hydatigena, and negatively to other cestodes. The complexity of these associations was better described with multivariate analyses than with bivariate ones and should be preferred when studying parasitic communities. The use of anthelmintics may thus modify the proportions of species in the community since their susceptibility to drugs is different.

\section{ACKNOWLEDGEMENTS}

We thank the Communal Hygiene Services of Constantine and Batna for their help in collecting dogs (P.N.R. F/009 20060067). We are grateful to the University of Constantine for funding a short stay of one of us in France (B. Bentounsi) that permitted planning of the present paper.

\section{REFERENCES}

[1] Choquette LP, Cayat C, Poue J. Note sur les helminthes trouvés chez le chien à Alger. Arch Inst Pasteur Algérie 1952; 30: 45-50.

[2] Lahmar S, Kilani M, Torgerson PR. Frequency distributions of Echinococcus granulosus and other helminths in stray dogs in Tunisia. Ann Trop Med Parasitol 2001; 95: 69-76.

[3] Pandey VS, Dakkak A, Elmamoune M. Parasites of stray dogs in the Rabat region, Morocco. Ann Trop Med Parasitol 1987; 81: 535 .

[4] Martinez-Moreno FJ, Lopez-Cobos HS, Becerra C, et al. Estimation of canine intestinal parasites in Cordoba (Spain) and their risk to public health. Vet Parasitol 2007; 143: 7-13.
[5] Hoida G, Greenberg Z, Furth M, et al. An epidemiological survey of Echinococcus granulosus and other helminths in animal populations in Northern Israel. J Helminthol 1998; 72: 127-31.

[6] El-On J, Shelef I, Cagnano E, et al. M. Taenia multiceps: a rare human cestode infection in Israel. Vet Ital 2008; 44: 621-31.

[7] Eckert J, Schantz PM, Gasser RB, et al. Geographic distribution and prevalence. In: Eckert J, Gemmell MA, Meslin FX, Pawlowski ZS, Eds. WHO/OIE Manual on echinococcosis in humans and animals: a public health problem of global concern. Paris. Office international des Epizooties 2001; pp 100-142.

[8] Pampiglione S. Recerche sulle presenza di Echinococcus granulosus nell' intestino del cane in Algeria. Parassitologia 1965; 7: 130-4.

[9] Pullola T, Vierimaa J, Saari S, et al. Canine intestinal helminths in Finland: Prevalence, risk factors and endoparasite control practices. Vet Parasitol 2006; 140: 321-6.

[10] Vanparijs O, Hermans L, van der Flaes L. Helminth and protozoan parasites in dogs and cats in Belgium. Vet Parasitol 1991; 38: 6773.

[11] Besbes M, Sellami H, Cheikhrouhou F, et al. L'abattage clandestin en Tunisie : enquête sur les connaissances et les pratiques des bouchers face à l'hydatidose. Bull Soc Pathol Exot 2003; 96: 320-2

[12] Portoles E, Granel P, Esteban JG, et al. Helminth associations in white-toothed shrews Crocidura russula (Insectivora: soricidae) from the Albufera National Park, Spain. J Parasitol 2004; 90: 5728 .

[13] Euzeby J. Diagnostic expérimental des helminthoses animales. Informations techniques des services vétérinaires. Ministère de l'Agriculture, Paris 1982

[14] Kassai T. Veterinary Helminthology. Oxford: Butterworth and Heinemann 1999

[15] Simstat. User's guide. Provalis Research, Montréal 1994

[16] Multivariate statistical package (MVSP). Users' Manual. Version 3.1. Kovach Computing services, Pentraeth 2001

[17] Budke CM, Campos-Ponce M, Qian W, et al. A canine purgation study and risk factor analysis for echinococcosis in a high endemic region of the Tibetan plateau. Vet Parasitol 2005; 127: 49-55.

[18] Schantz PM. Sources and uses of surveillance data for cystic echinococcosis. In: Anderson FL, Ouhelli H, Kachani M, Eds. Compendium on cystic Echinococcosis in African and Middle Eastern countries with special reference to Morocco. Provo: Brigham Young University print services 1997; pp. 72-84.

[19] Lahmar S, Lahmar S, Boufana B, et al. Screening for Echinococcus granulosus in dogs: Comparison between arecoline purgation, coproELISA and coproPCR with necropsy in pre-patent infections. Vet Parasitol 2007; 144: 287-92.

[20] Coman BJ. Helminth parasites of the dingo and feral dog in Victoria with some notes on the diet of the host. Aust Vet J 1972; 48: 456-61.

[21] Eguía-Aguilar P, Cruz-Reyes A, Martínez-Maya JJ. Ecological analysis and description of the intestinal helminths present in dogs in Mexico City. Vet Parasitol 2005; 127: 139-46.

[22] Dalimi A, Sattari A, Motamedi Gh. A study on intestinal helminths of dogs, foxes and jackals in the western part of Iran. Vet Parasitol 2006; 142: 129-33

[23] Wang CR, Qiu JH, Zhao JP, et al. Prevalence of helminths in adult dogs in Heilongjiang Province, the People's Republic of China. Parasitol Res 2006; 99; 627-30. 